\title{
Ética e política em Hans Jonas e Hannah Arendt ${ }^{1}$
}

\author{
Ethics and politics in Hans Jonas and Hannah Arendt
}

\author{
Éric Pommier*
}

\section{Resumo}

Para além do fato de comungarem as suspeitas contra os desenvolvimentos modernos da técnica e os riscos que eles representam para o mundo humano, Hans Jonas e Hannah Arendt se distanciam quanto às condições que permitiriam preservar um tal mundo. O primeiro nos convida a desenvolver uma ética da responsabilidade para com a vida enquanto a segunda desenha uma política da ação humana que escapa do ciclo vital. A constatação dessa divergência serve, no entanto, de pretexto para pensarmos uma complementaridade: a natalidade arendtiana pode receber uma justificação bioontológica e a ética jonasiana pode encontrar um modo de encarnação política na filosofia de Hannah Arendt.

Palavras-chave: Hans Jonas. Hannah Arednt. Técnica. Ética da responsabilidade. Ação humana. Natalidade.

1 Esse artigo teve sua primeira versão escrita em francês e publicada em: Revue de métaphysique et de morale, $2013 / 2 \mathrm{~N}^{\circ} 78$, p. 271-286 e se insere na pesquisa de pós-doutorado do Conicyt- Fondecyt no 3130574. Tradução de Jelson R. de Oliveira.

* EP: Doutor em Filosofia, e-mail: espommier@gmail.com 


\section{Abstract}

Beyond the legitimate suspicion against the recent developments of modern techniques and the risks that consequently threaten the human world, Hans Jonas and Hannah Arendt differ about the way to preserve such a world. The first one invites us to an ethics of responsibility for life whereas the other one draws the outlines of a politics made of human actions breaking with the vital cycle. The acknowledgement of this discrepancy gives us nevertheless the opportunity to think a complementarity between them. As the Arendtian natality can be justified from a bio-ontological point of view, Hannah Arendt's philosophy is able to provide the Jonassian ethics with a political incarnation embodiment. .

Keywords: Hans Jonas. Hannah Arednt. Techniques. Ethics of responsibility. Human actions. Natality.

\section{Introdução}

Embora do ponto de vista da vida vivida, possamos encontrar muitas razões para aproximar esses dois pensadores a seguir, parece, no que tange ao seu respectivo engajamento filosófico, ambos poderiam ser contrapostos um ao outro ${ }^{2}$. Enquanto Hans Jonas enfatiza uma ética de preservação da vida, enraizada em uma ontologia que restabeleceu o lugar do homem na natureza, Hannah Arendt, por sua vez, implementa uma filosofia mais política do que moral e insiste sobre uma certa ruptura entre a existência humana e a atividade biológica do vivo. Em um caso, portanto, parece que o homem tem obrigações morais para com a humanidade e a vida em geral porque é, ele mesmo, um vivente; enquanto no outro, é precisamente, porque é capaz de arrancar-se do ciclo alienante da vida que ele se abre para uma existência humana que lhe impõe uma série de tarefas específicas, de natureza política, com vistas à preservação de um mundo comum. Isso significa

2 Pensamos aqui na sua proximidade com Heidegger, sua relação com o judaísmo e à necessidade de se exilar da Alemanha nazista. Sua amizade, interrompida durante um tempo devido à publicação de Eichmann em Jerusalém, Relatório sobre a Banalidade do Mal, vai durar durante toda a sua vida. 
que Hannah Arendt e Hans Jonas compartilham uma mesma preocupação em relação ao risco de desumanização inerente à implantação de uma abordagem técnica da existência. Ambos apelam à responsabilidade que se dirige não tanto ao indivíduo, mas à coletividade, ou seja, às autoridades públicas. Tal posição é necessária devido a certa vulnerabilidade que marca a humanidade, cujo "vir ao mundo" requer que se assuma preocupações de tipo político ou ético. É no horizonte de uma ameaça que pesa sobre o mundo, que devemos entender a convergência dos pontos de vista desses dois pensadores que queremos expor nesse artigo. Mas também, é salientando as razões fundamentais que conduzem ambos os filósofos a propor diferentes soluções para esse problema, que nós seremos capazes de indicar os limites de cada uma destas soluções e sem dúvida também de ter a oportunidade de sua superação recíproca.

É através da consideração dos perigos que ameaçam a existência do homem moderno que Arendt, assim como Jonas, estão convencidos a defender soluções adaptadas à preservação de um espaço de vida, no qual o homem possa continuar realizando sua existência, naquilo que ela tem de mais autêntico, ou seja, de mais humano. Ora, ambos os autores expressam uma inquietação genuína em relação à crescente influência que a tecnologia tem sobre os nossos estilos de vida. A análise da tecnologia está no cerne da filosofia prática de Jonas. O uso da tecnologia moderna se caracteriza, segundo o filósofo, pela sua abrangência global e sua dinâmica. Enquanto o uso antigo da técnica se encontrava limitado no espaço e tempo, uma vez que os seus efeitos não afetavam mais do que o meio ambiente próximo e que o objetivo de uma existência poderia ser a aquisição de um saber-fazer relativamente estável, agora, os danos da técnica podem envolver todo o planeta e sua dinâmica consiste em uma superação permanente. $\mathrm{O}$ progresso se torna bom em si mesmo, e não porque serve para uma causa justa. O aprimoramento técnico não é mais um ponto final, mas apenas uma oportunidade para iniciar um novo desenvolvimento. A técnica escapa, em certa medida, à nossa vontade, porque nós somos cada vez menos livres para usá-la do modo como desejarmos. Ao contrário, ela se apresenta como um destino no qual 
nós somos os brinquedos. Podemos ser surpreendidos por esta constatação pessimista, na medida em que o homem continua, apesar de tudo, um sujeito que é livre para usar ou não este saber-fazer. A dificuldade, contudo, provém de um mal de tipo relativamente novo. Se uma ação pode ser, no plano intencional, individualmente boa, ela pode se tornar, ao contrário, desastrosa no nível coletivo quanto a seus efeitos. Ninguém é, assim, responsável a título pessoal por uma catástrofe que só foi possível pela acumulação das ações de todos. Tal pode ser o caso da poluição derivada do uso do automóvel, que impulsiona, em um plano global, o aquecimento do planeta ou os buracos na camada de ozônio. A gravidade da ameaça se associa à dificuldade de evitá-la. Já que a catástrofe resulta, de um lado, de ações que são louváveis a nível individual e que, portanto, não têm nada de condenável e, de outro lado, de ações que são prejudiciais em longo prazo. A catástrofe é lenta e não brutal. Sendo assim, é mais difícil gerar um medo saudável, porque aqui não podemos contar com um sobressalto salvador, mas necessitamos de um esforço que se sustente a longo prazo. O perigo de tecnologia não está limitado ao ambiente humano. Ela impacta diretamente sobre toda a vida. Jonas tem em vista aqui, as biotecnologias que intervém sobre o patrimônio genético do homem, podendo reificá-lo, transformá-lo em algo manipulável ao bel prazer, em vez de preservar a indeterminação na qual ele é mantido e que define o seu ser. De modo mais geral, tais ameaças objetivas provêm, de certa maneira, de se representar a vida como algo sobre o qual podemos agir a fim de obter um determinado resultado, de acordo com as exigências do rendimento, da rentabilidade e da eficiência. Trate-se dos seres humanos ou dos seres vivos em geral, estes são concebidos como meios a serviço de fins arbitrários, que dependem do desejo individual, das normas sociais do momento ou ainda do desejo de enriquecimento pessoal. Como podemos ver, a técnica é essencialmente um modo de ser, uma maneira de se relacionar com a existência e é em virtude da sua dimensão ontológica que ela pode ter efeitos muito reais no plano ôntico.

Ora, Arendt se associa até um certo ponto a essa análise proposta por Jonas. Sabe-se como em A condição humana, apresenta as 
condições antropológicos sob as quais o homem pode realizar uma existência verdadeiramente humana. Assim, a vida do labor é necessária porque permite a cada um conservar a sua vida, nutrir-se e entreter a máquina corporal, que é, por assim dizer, a base da existência humana. Mas, enquanto o trabalho é para Marx uma forma de abertura para o mundo, já que ele abre ao homem o futuro de si mesmo por meio da utilização de recursos humanos adequados, da inteligência e da vontade, este representa, ao contrário, segundo Arendt, um resto de animalidade que é preciso ultrapassar em direção ao uso e à realização das obras que têm a vantagem de quebrar o ciclo do consumo imediato em favor de certa durabilidade oferecida pelos trabalhos de artesanato e, sobretudo, da arte. $\mathrm{O}$ mundo humano requer alguma estabilidade que permite a cada um identificar-se e não se isolar em um devir alienante de absorção-destruição, característica do consumo. No entanto, este momento de uso deve ser ele mesmo ultrapassado em direção àquele da ação e do discurso (sobre o qual ele deverá regressar). Pois, o homem aí ainda se encontra escravizado a certa materialidade e exterioridade que o impedem de ascender a uma singularidade, que ele não pode obter a não ser em relação direta com seus semelhantes, graças a que, ele pode se consagrar à construção de um sentido para a vida comum e respeitosa da idiossincrasia. Fizemos essa breve retomada para trazer ao primeiro plano os riscos que pesam sobre a existência humana, os quais, como mostrou Étienne Tassin (1999, p. 208), podem ser ainda maiores na sociedade moderna. Segundo se reduza a existência ao trabalho ou à fabricação, inicia-se um processo de desumanização, de natureza totalitária, no segundo caso (já que a vida humana é regida por um imperativo de gestão regulamentada, a padronização do homem, porque cada um obedece a regras que eliminam qualquer possibilidade de singularização) e consumista, no primeiro. A existência humana, neste último caso, é, em seguida, reduzida à exigência impessoal e genérica de viver ${ }^{3}$. $\mathrm{O}$ anonimato da vida abole a existência individual.

3 "A única atividade que corresponde estritamente à experiência de ausência-do-mundo, ou melhor, à perda do mundo que causa dor, é a atividade de trabalho, na qual o corpo humano, malgrado sua atividade, é também rejeitado por si, se 
A renovação constante do consumo encerra o homem na repetição do mesmo. Essa é a maldição da tecnologia, que livraria o homem do esforço e ofereceria o prazer fácil, mas com a sua redução ao papel de consumidor, incapaz de apontar para um além, onde um sentido comum fosse possível. Enquanto o labor significou a penalidade, todos foram convidados a compreender o preço do consumo, que poderia compensar a abertura a um mundo de obras, constituído de bens de uso durável. Mas a técnica dá a recompensa sem pedir contrapartida. Por que então, procurar ultrapassar a vida que consome sem esforço, em direção a uma existência mais autêntica ${ }^{4}$ ? Este é, sem dúvida, o mal deste século. Todos trancados em sua idiotice, procurando a satisfação imediata e individualista que o artifício técnico agora torna possível, enquanto a construção de um espaço público torna-se a menor de todas as preocupações.

Entendemos bem, portanto, nesta breve apresentação, aquilo que conduz tanto Arendt quanto Jonas a denunciar os malefícios da técnica, mas também compreendemos porque o objeto de sua inquietude não é radicalmente idêntico. Se é correto afirmar que, tanto para um quanto para outro, a existência humana é colocada em perigo devido à técnica, é preciso acrescentar ainda uma diferença de fundo, que distancia Jonas de Arednt nessa análise aparentemente comum do problema. Assim, enquanto Jonas está alarmado com o fato de que a técnica coloca em perigo não só a vida humana, mas também a vida em geral, fato que o torna particularmente atento à necessidade de preservação das espécies vivas, Arendt considera o contrário, que a ameaça que pesa sobre o homem é a biologização que o confinamento do homem no consumo poderia resultar. Ela gostaria de manter a

concentra no fato de sua existência e continua a ser um prisioneiro de seu metabolismo com a natureza, sem jamais se livrar da recorrência cíclica de seu próprio funcionamento" (ARENDT, 2000, p. 163).

40 mundo aparece apenas com a presença de bens de uso. Porque eles são mais duráveis do que os bens de consumo, eles são o pólo de identidade que permite a o homem determinar o início e o fim de sua vida, e erguer o que acontece com ele em eventos pessoais, ao invés de simples fatos desprovidos de significação. Ele passa da biologia à biografia. 
abertura do homem ao mundo lembrando que ele é do mundo, o que significa que ele precisa dar continuidade à afirmação de si em um mundo de ações e de palavras, onde a pluralidade é lei. Jonas tem o mesmo objetivo, mas lembra que o homem provém da vida e que ela lhe dá aquilo que ele é, ou seja, a especificidade antropológica que emerge de uma crescente abertura ao mundo na medida mesma do progresso da vida ${ }^{5}$. Neste ponto, temos de fazer duas observações:

Em primeiro lugar, podemos tomar a medida de um possível mal-entendido. Sabemos que Arendt designa, com o termo natalidade, a possibilidade do homem se afirmar de maneira singular no seio do mundo, precisamente porque com ele vem uma nova promessa, pois ele é o lugar da imprevisibilidade. Sabemos também que Jonas vai assumir esse termo ao seu modo próprio ${ }^{6}$. Mas quando a filósofa considera um tal nascimento, esse conceito não tem de nenhum modo um sentido biológico, mas refere-se à capacidade do indivíduo de tomar lugar no seio de um mundo humano, iniciando novas ações. Não é, portanto, só por quebra da ordem orgânica na qual o trabalho nos mantém, mas também por meio do uso que requer de nós um saber-fazer padronizado, que se pode agir humanamente. Podemos ser tentados a culpar Jonas por fazer um uso abusivo do conceito arend tiano de natividade, uma vez que ele lhe atribui uma origem biológica. Tal é a denúncia feita por Gérôme Truc a Hans Jonas, pois ele considera que o filósofo alemão não leva em conta a dimensão ontológica da taxa de natalidade, que seria reduzida a uma compreensão puramente biológica ${ }^{7}$. No entanto, essa objeção ignora a dimensão ontológica da biologia jonasiana. Ora, não somente esta última permite compreender como o homem é capaz de abrir um mundo uma vez que tal abertura é delineada nas etapas precedentes da evolução vital, mas

5 Em 0 fenômeno da vida (2001), Hans Jonas mostra que o homem não se distingue do animal pela presença de uma alma suplantaria 0 corpo. Ele tenta substituir a temática dualista por uma compreensão da vida que mostra em que sentido 0 espírito tem um enraizamento orgânico e 0 organizmos já teria alguma coisa a ver com a subjetividade. A história da vida - desde a planta até o homem, passagendo pelo animal - não é mais do que o progresso de sua própria transcendência, graças à qual ela existe de maneira sempre mais livre, tanto no plano da ação quando no plano da "representação".

6 JONAS, 2000a, p. 53; е p. 405-406; JONAS, 1992, p. 150; JONAS, 2012, p. 60.

7 TRUC, 2008, p. 70: "Jonas tende a reduzir o termo natalidade a sua acepção biológica". 
também ela faz jus à especificidade característica do homem na sua maneira de se ligar ao mundo. Ansiosa para articular a unidade e a diferença entre o homem e a vida, a biologia filosófica de Jonas tem um caráter incontestavelmente ontológico, e isso porque a vida tem, a partir de suas formas mais rudimentares, certos caracteres da existência, algo que torna possível que ela adquira nos seres humanos, forma eminente do ser-em-vida, esta plena abertura ao mundo, que é designada pelo termo natalidade. A preocupação com a vida será então, em Jonas, imediatamente, uma preocupação com o mundo, enquanto a preocupação com o mundo em Arendt será um distancimaneto em relação à questão da vida.

Em segundo lugar, não podemos ignorar que esta divergência na maneira de se relacionar com o problema colocado pela tecnologia no que tange a sua ameaça tanto ao mundo da vida quanto ao mundo estritamente humano, provem de uma maneira diversa de se relacionar com a herança de Heidegger ${ }^{8}$. Heidegger vê no reinado da tecnologia o cumprimento da metafísica da subjetividade. A subjugação da questão do ser a um pensamento que objetiva tudo aquilo que é - e para a qual o sujeito é uma entidade não somente teórica que contempla o mundo de maneira exterior, como em um quadro que não tem nem profundidade nem obscuridade, mas que possui a nível prático uma vontade de dominar praticamente infinita - impede de apreender o ser desde o nada que lhe é constitutivo e que lhe inscreve na contingência radical. O único "meio" de superar esse recobrimento consiste, paradoxalmente, em "nada" fazer, uma vez que o ativismo teria, ao contrário, como consequência, o agravamento do mal que ele fez nascer. O apelo para a vontade de um sujeito, seja através de uma ética ou de uma política, seja convocando à responsabilidade ou convidando à ação e à tomada da palavra pública, levaria apenas ao agravamento do "mal", uma vez que se nutriria sempre a ilusão segundo a qual a "salvação" provém de um sujeito que tem uma representação plena e determinada do mundo ao qual pertence. Continuaria-se prisioneiro da metafísica da subjetividade.

8 Sabe-se que Arendt e Jonas foram ambos alunos de Heidegger, a partir de 1924 em Marbourg. 
A única maneira de se desprender é "deixar ser" serenamente e abandonar toda calma e abandonar qualquer conquista objectiva das coisas. Trata-se de acolher o ser, abrir-se para ele e, no recolhimento da meditação, de abrir-se ao mundo, respondendo a sua chamada. Mas este nível de análise, muito rapidamente evocado aqui, parece muito abstrato tanto para os olhos de Jonas ${ }^{9}$ quanto para os de Arendt. A técnica não é um destino, mas uma resposta à necessidade vital. Arendt vê a técnica como uma maneira de satisfazer nossa necessidade de consumo. Como tal, ela tem uma positividade e todo o mal vem de seu eventual caráter unilateral. O homem não pode acontecer para si mesmo, a não ser na condição de superar este modo de existência no qual ele não pode se realizar. Para passar da biologia para a biografia, para sair do modo impessoal e anônimo do ciclo vital a fim de ser alguém, ele precisa se abrir para um mundo, ele necessita que suas obras se tornem possíveis, o que, em algum sentido, consiste em romper com o puro ser-em-vida. Para Jonas também a técnica não é senão o prolongamento de um processo vital. Mas o significado que ele atribui a isso é, contudo, diferente. Enquanto que, para Arendt, viver é sobreviver, e esta é a última razão pela qual o confinamento no trabalho é alienante, Jonas vê na vida um movimento que abriga a liberdade, movimento que vai se alargando gradualmente à medida que avança o processo evolutivo que conduziu os primeiros germes da vida até a forma humana, depois de passar pela fase animal e vegetal. A técnica já é uma forma de estar no mundo própria ao homem e marca o aparecimento do poder de simbolizar, de fazer uso prático da faculdade imaginativa ${ }^{10}$. A técnica, por conseguinte, não será um perigo para Jonas porque ela nos encerra na vida, como é o caso em Arendt, mas, pelo contrário, porque ela nos distancia da vida, em

9 Jonas faz referência às razões evocadas antes dele por Spengler e Heidegger, para explicar o dinamismo técnico e ele argumenta que este é um terreno em que ele não vai retornar. Melhor ficar em um campo mais empírico. Cf. “Em que sentido a técnica moderna é um objeto para a filosofia", em Technik, Medizin und Ethik (J0NAS, 1985, p. 23). Veja-se também a versão em inglês deste texto em The Hastings Center Report 9/1, 1979, p. 36, no qual a crítica de Heidegger aí é mais direta.

10 JONAS, 2001, p. 180-181: "0 uso de nossas mãos mostra o tempo todo, esta tradução mortriz de forma, no seu significado prático mais vasto, como condição de qualquer técnica". 
virtude de uma dinâmica própria e "quase utópica"11, que leva o homem à destruição do seu meio-ambiente e da base biológica que torna possível a sua própria existência.

Compreende-se agora porque, segundo Arendt, convém resistir às forças que levam o indivíduo a retirar-se sobre si mesmo, sobre sua vida biológica - o que destrói o espaço público, único lugar onde cada um pode ser verdadeiramente si mesmo - graças a uma restauração da categoria da ação. Ao contrário, para Jonas, é necessário pensar as condições para o respeito desta vida que nos faz ser quem somos. Segundo ele, é somente preservando o mundo da vida que o homem pode continuar a ter um mundo, enquanto que, para sua amiga, é somente resistindo ao ciclo devorador da vida que encoraja a tecnologia que se pode preservar o mundo.

Para pensar as condições desse mundo humano, Hannah Arendt lançou mão da categoria da ação. Se o homem tem o poder de agir, é em virtude da natalidade, que lhe permite começar completamente uma série de efeitos. Este sentido de iniciativa, não é o efeito de alguma causa antecedente absolutamente determinante, mas é a própria causa de novos efeitos. Este poder de novidade define a existência humana e a faz escapar tanto da monótona repetição do serviço vital quanto da mecanização da existência, consecutiva à implementação de um saber-fazer em geral. Mas a ação deve, igualmente, ser narrada em um espaço público se quisermos que ela revele sua significação. É só na biografia que o indivíduo advém a si mesmo, sob a condição de declarar o que ele é dizendo aquilo que ele faz e distinguindo-se dos outros. O homem nasce para o mundo, porque ele tem o poder de começar algo inédito no seio da pluralidade à qual ele pertence e porque é capaz de comentar sua ação:

11 JONAS, 2000a, p. 417. Cf. igualmente: JANICAUD, 1993, p. 102. 
Agindo e falando, os homens fazem ver que eles são, revelam ativamente suas identidades pessoais únicas e fundam, assim, sua aparição no mundo humano, enquanto suas identidades físicas aparecem sem qualquer atividade, na unicidade da forma do corpo e do som da sua voz. Esta revelação do "quem" em oposição a "o quê" - as qualidades, os dons, os talentos, as faltas de alguém, que ele pode difundir ou dissimular - está implícita em tudo o que fazemos e tudo o que dizemos. (ARENDT, 2000, p. 236)

A ação transcende a atividade produtiva, porque é o próprio homem que se mostra através dela. Sua identidade, tal como se apresentava no tecido das relações humanas, é o objeto direto de sua construção. Agindo, ele pode descobrir quem ele é e escapar da alienação que implicaria a adesão a mundo puramente instrumental.

Mas a natalidade que é promessa de mundo é também sua ameaça ${ }^{12}$. Por um lado, de fato, a novidade do nosso trabalho gera efeitos, em parte, imprevisíveis. O caos que nossa ação pode introduzir no mundo pode nos dissuadir de agir. Vale a pena realizar alguma coisa quando as conseqüências dos atos podem se voltar contra sua intenção e na medida em que não podemos prever tudo o que vai acontecer? Mas essa ansiedade legítima sobre o futuro da nossa ação, por outro lado, faz eco à dor da irreversibilidade do tempo, da impossibilidade de desfazer as consequências negativas de nossas iniciativas, marcadas na encruzilhada da unicidade. "O que está feito não pode ser desfeito"13, constata Lady Mac Beth com as mãos manchadas de sangue. Nisso reside a fragilidade do mundo. Ele comporta sua própria ameaça interna, na qual o espectro do totalitarismo ou da utopia pode se infiltrar e desumanizá-lo ${ }^{14}$. Embora as atividades precedentes incluíam seus

12 ARENDT, 2000, p. 249: "A fragilidade das instituições e das leis e, geralmente, tudo o que se diz respeito à comunidade dos homens provem da condição humana de natalidade"

13 Mac Beth, ato V, cena 1, 68, Shakespeare.

14 Arendt observou que Platão é o primeiro a querer resolver o problema da fragilidade dos assuntos humanos, eliminando 0 acaso e a irresponsabilidade consecutiva à pluralidade dos agentes, que são atores, mas jamais autores, uma vez que, de uma parte, eles são sempre também objetos passivos e, por outra, as consequências de suas ações não são plenamente previsíveis. Mas substituindo esse jogo de claro-escuro da ação, a transparência instrumental do fazer, ele suprime ao mesmo tempo o espaço público. A política consistiria em tomar conhecimento da pluralidade à qual a ação está ligada como um fato irredutível. 
próprios limites que exigiram uma superação na esfera seguinte, eis que agora nada se oferece para além da ação e é por isso que ela é vulnerável. As leis e as instituições humanas podem se desfazer se os homens não se envolverem e não as mantiverem na existência por meio de sua ação e discurso. Se eles não tiverem a coragem de começar as ações apesar da incerteza de suas consequências, então o mundo não poderá se renovar para atender às exigências do momento e permitir que os homens se afirmem em suas singularidades. É no seio mesmo do agir, portanto, que temos de encontrar um antídoto às suas próprias falhas. E é para esse fim que Arendt convoca as categorias políticas da promessa e do perdão. A promessa me liga a um futuro que eu decido e que me permite superar os perigos. Mas o perdão é o suplemento que ajuda a livrar o agente de seus erros passados, de suas falhas, a fim de que a vida pública seja possível ${ }^{15}$. É sob esta dupla condição que os homens podem cumprir sua vocação de serem destinados a começar algo novo.

No entanto, decidindo assim as condições de um mundo humano, Arendt parece subestimar o perigo da técnica diante da vida e do futuro da humanidade. O problema, neste caso, eminentemente contemporâneo, é que ambos não pertencem ao espaço público. Nada sustenta seu direito à existência sob a ameaça da globalização e do frenesi tecnológico. A ação humana, tal como Hannah Arendt previu, parece impotente para pensar a obrigação de evitar o perigo que ameaça este tipo de ser. Nada proíbe, no plano político, que os homens de hoje saqueiem o meio ambiente ou realizem mudanças na base genética que afetarão seus descendentes. Então, quando a ameaça diz respeito à natureza, à vida e até mesmo à humanidade por vir, nada pode frear as iniciativas humanas e as categorias da promessa e do perdão já não podem ser invocadas para resolver estas dificuldades. Como escreveu Jean Greisch:

15 Paul Ricoeur parece duvidar da existência de um perdão de tipo político (ARENDT, 2000, Prefácio, p. 31 e Memória, História, Esquecimento, 2000, p. 633-636.) Podemos nos perguntar se a instituição dos tribunais de "verdade e reconciliação", tal como houveram ou tal como ainda há na África do Sul e na América Latina, segundo modalidades diferentes em ambos os casos, não se baseia mais ou menos em tal idéia. Invictus, de Clint Eastwood, dá um sentido político para o perdão e o torna uma acção-chave de Mandela, que lhe permite recuperar a unidade nacional. 
Tudo se passa como se nessa situação, os dois grandes remédios que são o perdão e a promessa se tornassem inoperantes. A natureza não é capaz de nos perdoar e é por isso que pedir perdão pelos erros da ação humana não tem nenhum sentido. Da mesma forma não é senão em um sentido bastante metafórico que se pode falar de um "contrato natural", que implicasse a dimensão da promessa (GREISH, 1996, p. 89).

Ora, a força do pensamento jonasiano consiste precisamente em tomar esse tipo de problema como ponto de partida, argumentando que a vida humana não tem sentido quando pensada independentemente da preservação da natureza e das demais condições que tornam a vida em geral possível. Sem entrar nos detalhes da demonstração implementada em O Princípio Responsabilidade, contentemo-nos em observar que o autor mostra como a vulnerabilidade da vida e das futuras gerações exige uma atitude atual do homem. Porque a vida se apresenta como um bem em si mesmo e sua perpetuação depende do controle que temos sobre o nosso próprio poder tecnológico, é ele, justamente que nos obriga a ser responsáveis por ela, que se declina sempre no futuro, na medida exata onde ela se define sobretudo pela própria possibilidade que ela é ${ }^{16}$. Vemos aqui que a fragilidade não é aquela das instituições humanas. Dizemos mais, que se trata da vulnerabilidade da natureza em geral e da vida em particular. Poderíamos então, ousar a formulação seguinte: porque a vida é o lugar de indeterminação e porque a vida humana exacerba esse poder de indeterminação, que o agir humano é o mais frágil de todos os modos de ser. Ele exige a responsabilidade particular do homem para assegurar a perenidade. $\mathrm{O}$ homem deve exercer um controle ético sobre o seu próprio agir (tecnológico) em nome dessa vulnerabilidade da vida, que é acentuada na forma desta vida particular que é a existência humana, e que isso o conduz a se tornar responsável pelas futuras gerações.

${ }^{16}$ Ver JONAS, 2000a, p. 267: "Mas 0 que importa agora não é perpetuar uma determinada imagem do homem, nem de a suscitar, mas primeiro de manter aberto o horizonte de possibilidade que, no caso do homem, é dado com a existência da espécie como tal [...]". 
Pode-se então, considerar que a natalidade, tal como a entende Jonas, é a condição ontológica da natalidade tal como entendida por Arendt. Se o mundo humano se revela frágil ao ser entregue aos recém-chegados - que gozam do poder de criar novas possibilidades de existência, mas que são também a condição de renovação do mundo - nós temos que encontrar a fonte de tal natalidade no movimento mesmo da vida, que se define por esse poder, especialmente no homem, de fazer surgir possibilidades inéditas. É preciso, então, reconhecer que a fragilidade das instituições humanas requer a responsabilidade dos políticos em vista de sua proteção, pressupõe examinar o fundamento mesmo desta fragilidade, ou seja, desta natalidade, e trazer ao conceito sua condição de possibilidade ontológica, a saber, o ser mesmo da vida. Mas é, então, até um imperativo de responsabilidade para com a vida que somos conduzidos, como aquilo que deve preservar a fonte mesma da renovação humana, da natalidade, graças à qual o homem pode nascer no mundo, increver-se em uma comunidade fazendo-a evoluir. Mas para que haja política nesse caso, e porque somos responsáveis pela fragilidade institucional, devemos primeiro reconhecer que é da vida que o poder da novidade, que "se exacerba no homem", provém, e que é ela que reclama uma responsabilidade específica e originária.

Ora, é precisamente esta ancoragem biológica da responsabilidade que Arendt não pode subscrever e que testemunha a analogia, proposta por Jonas, com a responsabilidade parental. Assim como a existência da criança é totalmente dependente dos cuidados do pai, o qual, por sua força, pode promover ou impedir esta existência, as gerações futuras são esta criança frágil, cuja perenidade depende da nossa responsabilidade. Não podemos, de fato, segundo Arendt, colocar sobre o mesmo plano uma responsabilidade familiar e uma responsabilidade de tipo político, pois a noção de contrato só permite fundar a comunidade humana entre seres livres e iguais. A existência política, além disso, se atesta por retirar qualquer determinação biológica. Jonas relata em suas Memórias, a reação de sua melhor amiga, depois de ler as páginas d'O Princípio Responsabilidade, consagradas à teoria da responsabilidade. Após ter elogiado a obra, Arendt expõe suas reservas: 
Então, ela se recusou completamente a ideia de que a principal responsabilidade do homem possa estar fundada biologicamente sobre a ordem natural. Isso consistia, a seus olhos em um relatório livremente instituído, que resultou da Polis, da vida coletiva e do caráter estatal ou político e não familiar. Ela lembrou de Aristóteles, que operou uma distinção clara entre a esfera privada da associação da família e a esfera pública da comunidade cívica. Ela foi bastante firme quanto a isso, acreditando que uma coisa como a responsabilidade com o bem comum era artificial em sua essência e não natural, que a responsabilidade deriva do "contrato social", de acordo com a tradição ocidental (JONAS, 2005, p. 245). ${ }^{17}$

De fato, a filosofia de Arendt toma o cuidado de distinguir entre a responsabilidade familiar, escolar e política ${ }^{18}$. Se os pais estão envolvidos na manutenção da vida e protegem as crianças de uma incursão prematura no mundo, de uma exibição pública irresponsável de sua vida privada, cabe à responsabilidade política, por sua vez, proteger o mundo da chegada incessante das novas gerações, que poderiam comprometer a perenidade deste mundo, em caso de uma não-preparação. Essas responsabilidades são distintas, mas complementares. Porque o mundo está sendo protegido dos recém-chegados, é possível perpetuar uma tradição e manter uma estabilidade que permite à criança se inserir nesse mundo e nele produzir o novo. Não somente esta novidade permite à criança realizar-se humanamente, pois a essência do homem é iniciar novos movimentos, mas também permite que o mundo evolua e, portanto, se mantenha. O conservadorismo político o levaria, de fato, para a ruína. Mas, inversamente, é porque a criança é mantida no espaço familiar, e não jogada como alimento no mundo, que não somente este escapa da privatização do espaço público, que tem valor de destruição, mas, além disso, a criança pode então ser oportunamente inserida em um mundo que the tenha sido preparado. Em caso contrário, a realização imediata e infantil da novidade seria inútil, incapaz de se religar ao pólo de estabilidade que é oferecido pelo mundo. Que significado teria a novidade, se ela se torna um processo permanente? Contrastando

\footnotetext{
17 A propósito da distinção aristotélica, cf. por exemplo: Éthique à Nicomaque, 1134 b 9-17 (ARISTÓTELES, 1994, p. 250).

${ }^{18}$ (f. ARENDT, 1998, p. 223-252 («La crise de lséducation»).
} 
fortemente a responsabilidade familiar e a responsabilidade política, Hannah Arendt preserva simultaneamente o espaço público e espaço privado, que poderiam, no caso contrário, colidir um com o outro. Cabe então à instituição escolar estabelecer uma mediação bem-sucedida entre a vida e o mundo. Na verdade, não somente os professores possuem uma tal competência, mas eles também têm uma autoridade que lhes vem de seu conhecimento do mundo. Este conhecimento e até mesmo o reconhecimento do mundo tal como ele é, mostram o seu compromisso e os torna aptos para preparar a criança. A escola não é uma mera parte do mundo, mas ela é o lugar privilegiado que o prepara. É porque a educação é conservadora e baseada em uma doutrina tradicional, que a política pode ser inovadora. A criança torna-se um homem, dando início a novas ações em um velho mundo, que apela por uma renovação, em vista de sua manutenção. Para permanecer como cidadãos activos, é necessário que o pai cuide da vida, e somente da vida da criança, e que o professor assuma o mundo para que a criança nele se insira. Mas se a autoridade ou a responsabilidade para com o mundo se relava em crise, então o risco de ver a escola abandonar sua vocação e do espaço privado invadir e cobrir o mundo, é grande. Tal é a preocupação que Arendt alimenta em relação à pedagogia moderna, que postula o "mundo da criança", prejudicial não somente para a criança que não tem mais um mundo verdadeiro - onde prevaleça a igualdade e a liberdade - no qual se inserir (ARENDT, 1998, p. 223), mas também o mundo ele mesmo, que não pode mais evoluir por não ter preservado e levado à maturidade este senso da novidade segundo pelo qual o homem é pesado e do qual a criança é a promessa, é por isso que a essência da educação é a natalidade (ARENDT, 1998, p. 224).

Mas a crítica arendtiana da naturalização da política por parte de Jonas aparece como uma reserva. Ou, poderíamos assinalar, sob a forma de uma crítica muito mais radical: seria, de fato, precisamente porque Jonas toma por modelo, a fim de pensar a relação política, a responsabilidade dos pais em relação aos filhos, responsabilidade que também estaria inscrita na natureza, que seu pensamento poderia resultar em elogio de regimes autocráticos. Compreender a relação das pessoas com o soberano a partir da relação da criança com o pai, é esquecer 
que as pessoas são seres autônomos que participam da soberania do Estado. Eles não são simplesmente indivíduos que obedecem a autoridades que sabem onde está o bem. Eles são membros ativos do Estado com o qual contribuem para definir as suas missões. Adotando como modelo da responsabilidade política a responsabilidado do pai, Jonas seria levado a promover regimes autoritários que se sentem encarregados pelo povo de maneira unilateral. Tal seria também o verdadeiro sentido do impasse político que conclui O Princípio Responsabilidade, que não encontraria nenhum outro regime, a não ser um autoritário, capaz de incorporar a ética da responsabilidade para com as gerações futuras. A transição da ética à política seria comprometida ao se pensar a autonomia da política em relação à esfera natural, portanto.

No entanto, essa crítica é baseada em um mal-entendido. Devese notar, em primeiro lugar, que a responsabilidade parental não é o modelo de responsabilidade política. Um e outro tipo de responsabilidade são, ao contrário, modelos para pensar uma responsabilidade que os ultrapasse e que é a responsabilidade ética para com a vida e as gerações futuras. Jonas os seleciona porque sua estrita oposição - um é natural, ou seja, fornece um ser singular e eminentemente prático, enquanto o outro é artificial, ou seja, diz respeito a um ser coletivo e é abstrato - no entanto, sugere características comuns que circunscrevem a essência da responsabilidade numa ética que deve pensar os novos deveres para com a vida e as gerações futuras. Em ambos os casos, de fato, trata-se de abordar um ser vulnerável que requer de um poder um apoio que, se ele venha a falhar, levará ao definhamento do ser criança ou povo - que requer os cuidados apropriados. Em ambos os casos, trata-se igualmente de pensar o acesso ou a preservação da autonomia dos homens e, portanto, da sua responsabilidade. Este jogo de comparação permite pensar sem, contudo, fundar, uma responsabilidade pela vida e a humanidade vulnerável. Portanto, não há aqui uma naturalização da política. Deve-se acrescentar, em segundo lugar, que Jonas mantém explicitamente a distância que existe entre o poder paternal e a responsabilidade política ${ }^{19}$. Como ele escreve, por exemplo:

19 Cf. por exemplo: JONAS, 2000a, p. 191-192. 
Como um elemento natural [o amor da comunidade em comparação com amor filial] está também contido no officium artificialmente criado do homem de estado, uma vez que, estando para fora da comunidade dos irmãos e dos cidadãos, ee assume em nome de todos eles, um papel que inclui responsabilidades semelhantes às de um pai - embora o parentesco natural não tenha nada a ver com a solidariedade [que se realiza entre iguais] (JONAS, 2000a, p. 205-206).

Resta-nos ainda, de fato, uma dificuldade para pensar, no sistema jonasiano, uma política que possa assumir a realização do princípio ético formulado por Jonas. Isto é ainda mais surpreendente quando nos damos conta de que o filósofo pretende apresentar uma ética que pode ter uma eficácia pública ${ }^{20}$. Depois de fundar seu princípio, Jonas busca um sistema capaz de encarná-lo. No entanto, nem o modo capitalista de organização, nem o modo comunista - é verdade que esses são menos regimes políticos do que sistemas econômicos - parecem favoráveis, como tal, para incorporar a nova ética. A preocupação com o curto prazo e o individualismo de um e o produtivismo do outro, são algumas das razões que levam Jonas a rejeitá-los. É verdade que algumas pistas devem ser, contudo, evocadas. Um "socialismo desencantado", privado do aparato utópico que anima o marxismo e conduz a um frenesi tecnológico, tem suas vantagens. O apelo à realização de grandes convenções internacionais, à sensibilização de jovens nas escolas está lançado. Tais mediações são necessários, se quisermos evitar uma ditadura, supostamente benevolente e orientada para os interesses da humanidade, mas oferece poucas garantias. Em Jonas, ela atua mais como uma ameaça do que como uma recomendação (cf. JONAS, 2000a, p. 149-150). Mas todas essas observações não têm valor de doutrina. Jonas não pretende ter descoberto uma filosofia política. O Princípio Responsabilidade é, antes de tudo, um livro que expõe um princípio ético e que, assim, adota uma abordagem ética, uma vez que ilumina as consciências e contribui para orientar o comportamento. Mas é também esta a razão pela qual a filosofia política de Jonas permanece ainda

20 JONAS, 2000a, p. 41: "É claro que o novo imperativo se dirige muito mais à política pública do que à conduta privada". 
como algo a ser escrito. Mais precisamente: continua aberta a questão de saber como encarnar o princípio responsabilidade no espaço público. Esta análise exigiria um aprofundamento quanto ao sentido deste princípio. Limitemo-nos aqui a uma observação. Este princípio é, antes de tudo, uma fonte de reflexão que tem uma vocação normativa. Tratase, com efeito, de reconhecer o valor da vida a partir da vulnerabilidade que ela mesma testemunha. Como tal, o princípio convida a nos preocuparmos com o que pode acontecer devido à temeridade tecnológica. Ele é, portanto, imediatamente congruente com uma "heurística do temor", cujo papel é o de antecipar ameaças futuras e animar a vontade de prevenir possíveis desastres. O princípio está aí, antes de tudo, para desenvolver toda uma área de pesquisa deixada de lado e que consiste em interrogar sobre o equilíbrio dos ecossistemas, as condições para uma vida não robotizada. Ele está aí, também, para informar os cidadãos a fim de que eles se interroguem sobre os verdadeiros bens que a investigação científica deve buscar. Dessas reflexões poderão, então, nascer várias obrigações derivadas ${ }^{21}$, que dariam lugar a uma macroética, ainda a se construir. No direito pode-se supor que isso implique a colaboração da consciência pública e cidadã, pois todos os atores podem ser envolvidos, do mais informado ao menos informado. Está igualmente permitido imaginar que a força desta obrigação se imporá ainda com mais necessidade do que o próprio público terá contribuído para fazer surgir. Os comitês de ética, as convenções internacionais, os comitês de cidadãos... são estas instituições que podem desempenhar o papel de mediadoras entre a consciência comum e a consciência responsável, entre os interesses egoístas e preocupação com a humanidade e a vida. Ora, é aqui que a filosofia política de Hannah Arendt pode compensar a fragilidade do sistema jonasiano. A categoria da ação é a base a partir da qual podemos entender a intervenção do homem na cidade, de modo que ele tome parte na vida pública e contribua para determinar o seu curso.

21 Por exemplo, a perspectiva de um dia recorrermos à clonagem humana traz à luz um direito à ignorância. Trazendo clones ao mundo, predeterminari-se a existência do indivíduo e prejudicaria-se a sua autenticidade, o seu direito de viver uma vida aberta às possibilidades indeterminadas. 
Assim, parece que à política sem ética de Hannah Arendt, podemos acrescentar a ética sem política de Hans Jonas. Este último oferece um princípio frutífero, uma fonte para orientar a reflexão pública e provocá-la a produzir uma macroética, que terá uma força de convicção ainda maior do que aquela que tem resultado da elaboração comum. Mas esse princípio dos princípios permanece não-político. Ele respousa sobre uma base ontológica, que só permite pensar um respeito pela vida e as gerações futuras. É isto precisamente o que estava faltando no pensamento de Arendt. E é essa ontologia da vida que permite pensar a emergência, no homem, da liberdade e da reflexão, necessárias para a ação política. Em outras palavras, a concepção restritiva que Arendt teve da vida, a impediu não somente de compreender como o agir humano poderia se dar, mas provavelmente também, como a vida e a natureza poderiam reivindicar respeito. Mas inversamente, ainda, Jonas não pensou em como a sua ética poderia se pluralizar em uma série de obrigações reconhecidas por todos e capazes de serem incorporadas no espaço público. Este é o caminho que Hannah Arendt, sua amiga de sempre, parece oferecer-lhe ${ }^{22}$.

\section{Referências}

ARENDT, H. La Condition de l'homme moderne. Paris: Nathan, 2002.

ARENDT, Hannah. La Crise de la culture. Trad. fr. P. Lévy. Paris : Folio essais, 1998 ARISTÓTELES. Éthique à Nicomaque. Trad. fr. J. Tricot. Paris: Vrin, 1994.

GREISH, Jean. «L Lamour du monde et le principe responsabilité » In: VACQUIN, M. (Dir.). La Responsabilité. La condition de notre humanité. Paris : Autrement, 1995 («Série Morales » n. 14).

JANICAUD, D. « L'adieu critique aux utopies », In: HOTTOIS, Gilbert (Dir.) Aux fondements d'une éthique contemporaine. H. Jonas et H.T. Engelhardt. Paris: Vrin, 1993.

22 É notável que no momento de render homenagem à amiga falecida e de evocar a sua filosofia, Hans Jonas escolhe os temas do trabalho, do labor e do pensamento, deixando de lado o tema da ação... (Cf. JONAS, 1996, p. 95). 
JONAS, Hans. « Agir, connaître, penser. Contribution à l`œuvre philosophique de Hannah Arendt » In : Entre le néant et l'éternité. Trad. fr. S. Courtine-Denamy. Paris: Belin, 1996.

JONAS, Hans. Évolution et liberté. Trad. fr. S. Cornille et P. Ivernel. Paris: Payot, 1992.

JONAS, Hans. L'Art médical et la responsabilité humaine. Trad. fr. E. Pommier. Paris: Les éditions du Cerf, 2012.

JONAS, Hans. Le Phénomène de la vie: vers une philosophie biologique. Trad. fr. Danielle Lories, Bruxelas, De Boeck, 2001

JONAS, Hans. Le Principe responsabilité. Trad. fr. J. Greisch, Paris, Flammarion, 2000a.

JONAS, Hans. Souvenirs. Trad. fr. S. Cornille et P. Ivernel. Paris : Payot Rivages, 2005

JONAS, Hans. Technik, Medizin und Ethik. Frankfurt am Main: Suhrkamp, 1985 (versão em inglês: The Hastings Center Report 9/1, 1979, p. 36)

JONAS, Hans. Une éthique pour la nature. Trad. fr. S. Courtine-Denamy. Paris : Desclée de Brouwer, 2000b.

RICOEUR, Paul. Memória, História, Esquecimento. Paris: Seuil, 2000.

TASSIN, Étienne. Le Trésor perdu. Hannah Arendt, l'intelligence de l'action politique. Paris : Payot, 1999.

TRUC, Gérôme. Assumer l'humanité. Hannah Arendt: la responsabilité face à la pluralité. Bruxelles: Éditions de l’Université de Bruxelles, 2008 (« Philosophie et société »).

Recebido: 10/12/2015

Received: $12 / 10 / 2015$

Aprovado: 28/01/2016

Approved: 01/28/2016 
